\title{
The Neuroleptic Treatment of Schizophrenia: Dosing Strategies, Depot Preparations and Novel Medications
}

\author{
Alexander S. Young M.D. \\ Research Fellow, Robert Wood Johnson Clinical Scholars Program, Departments of Medicine and \\ Psychiatry, UCLA and West Los Angeles Veterans Affairs Medical Center, Los Angeles, California
}

Follow this and additional works at: https://jdc.jefferson.edu/jeffjpsychiatry

Part of the Psychiatry Commons

Let us know how access to this document benefits you

\section{Recommended Citation}

Young, Alexander S. M.D. (1996) "The Neuroleptic Treatment of Schizophrenia: Dosing Strategies, Depot Preparations and Novel Medications," Jefferson Journal of Psychiatry. Vol. 13 : Iss. 1 , Article 4.

DOI: https://doi.org/10.29046/JJP.013.1.003

Available at: https://jdc.jefferson.edu/jeffjpsychiatry/vol13/iss1/4

This Article is brought to you for free and open access by the Jefferson Digital Commons. The Jefferson Digital Commons is a service of Thomas Jefferson University's Center for Teaching and Learning (CTL). The Commons is a showcase for Jefferson books and journals, peer-reviewed scholarly publications, unique historical collections from the University archives, and teaching tools. The Jefferson Digital Commons allows researchers and interested readers anywhere in the world to learn about and keep up to date with Jefferson scholarship. This article has been accepted for inclusion in Jefferson Journal of Psychiatry by an authorized administrator of the Jefferson Digital Commons. For more information, please contact: JeffersonDigitalCommons@jefferson.edu. 


\title{
The Neuroleptic Treatment of Schizophrenia: Dosing Strategies, Depot Preparations and Novel Medications
}

\author{
Alexander S. Young, M.D.*
}

\begin{abstract}
Significant progress has been made over the past decade in the use of antipsychotic medication. An improved understanding of neuroleptic side effects has led to the development of new clinical strategies for dosing traditional medications. Traditional medications have become widely used in depot preparations. Risperidone, a new medication with an improved side effect profile, has recently become available. Clozapine, a novel medication, has entered widespread use. The use of these new clinical technologies is briefly discussed, along with the implications they have for the role of the psychiatrist in community mental health settings.

Neuroleptic medication has been widely used in the treatment of schizophrenia since the 1950's. Over the past decade, however, we have seen significant advances in our understanding of these medications $(1,2)$. Only recently, for instance, has the effect of dose on efficacy and side effects been elucidated. This has led to more refined dosing strategies, with an increased appreciation for the toxic effects of these medications. Long acting decanoate preparations have also become better understood, and have entered widespread clinical use. Indeed, decanoate preparations can now be seen as the preferred medication for many chronically ill patients. Finally, a great deal of excitement has been generated by the development of novel medications with increased efficacy and decreased side effects. Clozapine and risperidone have become widely available, and experimental medications such as olanzapine are showing great promise. The availability of new medications has combined with an improved understanding of psychopharmacology to make optimal medication management more complex. This presents a unique opportunity for psychiatrists to take a leadership role in community mental health treatment organizations as a skilled psychopharmacologist.
\end{abstract}

\section{DOSING STRATEGIES}

Only recently have researchers begun to elucidate the effect of neuroleptic dose on response and toxicity $(3,4)$. Previously there was a general belief that more was

\footnotetext{
*Research Fellow, Robert Wood Johnson Clinical Scholars Program, Departments of Medicine and Psychiatry, UCLA and West Los Angeles Veterans Affairs Medical Center, Los Angeles, California.
} 
better, and that little harm could come from high doses. Indeed, clinical strategies, such as "rapid neuroleptization" advocated the use of high-dose treatment of acute psychosis. These approaches did not withstand careful study (5). Indeed, researchers have recently found a dose-response curve for conventional neuroleptics in which moderate doses produce maximal improvement (6). The optimal dose for acute psychosis appears to be in the range of $10-15 \mathrm{mg}$ per day of haloperidol $(4,7)$, and some studies suggest that patients improve on substantially lower doses (8). While there has been less research on the dose-response characteristics of other conventional neuroleptics, a similar relationship has been suggested for fluphenazine, trifluoperazine and thiothixene (9). While typical dosage levels vary between different neuroleptics, conversion factors allow doses of each neuroleptic to be understood as an approximate haloperidol equivalent dose (10).

Of course, there is the rare patient who actually benefits from more than 10 or $15 \mathrm{mg}$ per day of haloperidol. Why, therefore, take a chance by tapering a patient's dose? There are several very convincing reasons for tapering doses, with the goal of establishing the minimum effective dose for every patient. First, it is likely that many patients on very high doses of neuroleptic are, in fact, minimally responsive or nonresponsive to neuroleptics. Between 10 and $40 \%$ of people with schizophrenia are nonresponsive to traditional neuroleptics (11). These patients often get their doses steadily increased in an attempt to control persistent symptoms, resulting eventually in sedation and chemical restraint. Often these patients can be managed quite well with low dose neuroleptic combined with behavioral therapies such as social skills training (12) or a potent benzodiazepine such as clonazepam (13).

The risk of tardive dyskinesia is well known, and is thought to occur in approximately $4 \%$ of patients for every year of neuroleptic exposure (14). While tardive dyskinesia has not been proven to be dose-related, there are strong theoretical and experimental reasons to believe that dose may play an important role (15). There has also been an increased recognition of the acute side effects of oral neuroleptics. Acute extrapyramidal side effects, such as dystonias, are well-known and dose-related. Akathisia is dose-related, can be difficult to treat, and may lead to behavioral disturbances and treatment noncompliance (4). Other common side effects, including apathy, anhedonia, and akinesia, are similar to the negative symptoms of schizophrenia, and therefore easy to overlook. While some of these side effects can be ameliorated with medication, others, such as sexual dysfunction, are generally resistant to anything other than a change of dose or medication. Finally, there is recent evidence that vocational and social functioning worsens on higher doses of neuroleptics $(16,17)$.

Since neuroleptics can have adverse effects at even moderate doses, clinicians need to titrate carefully dose and effect (18). Even if a moderate dosage is effective in producing a remission of positive symptoms, a lower dose may be adequate for averting a major relapse. However, intermittent dosing or "drug holidays" have been shown to significantly increase the chance of relapse, and are not generally recommended (2). One should assume that, at any given time, there is an optimal dose for each patient which can be found by weighing beneficial and adverse effects. It is not 
uncommon for this optimal dose to be below that needed to remove all psychotic symptoms. Maximal functioning may often be achieved even when the patient continues to have some psychotic symptoms. Therefore, it is crucial that patients be taught to recognize symptoms and side effects, and to communicate these to their physician. While this sort of education can be time consuming, it has been shown to reduce relapse (19). Patients can be taught to rate each important symptom and side-effect on a daily basis. When the physician uses this information and completes a Brief Psychiatric Rating Scale (20) at each visit, the "minimal effective dose" can be readily determined. This dose, when faithfully used, allows the patient to maximize functioning and quality of life.

There is good reason to believe that the effective use of neuroleptic medication requires an integration of psychopharmacology and psychosocial rehabilitation (21). For instance, psychiatrists need to know how a patient is functioning in order to arrive at an optimal medication regimen. Also, patients need to have access to intensive psychoeducational programs that teach them about the symptoms of their mental illness and the side effects of their medication. This education may, in many organizations, be most cost-effectively performed by a non-psychiatrist. These collaborative approaches require, however, that the psychiatrist is available to supervise other clinicians about medication and communicate with them regarding the current status of rehabilitation efforts. This collaboration is not likely to occur if the psychiatrist is not an integral member of the treatment team. Community mental health organizations that limit psychiatrists to signing prescriptions are unlikely to provide the full benefits of modern psychopharmacology to their patients.

\section{DEPOT PREPARATIONS}

Injectable depot neuroleptics should be considered in all people with chronic psychotic illness, and should guide the initial choice of oral medication. Use of injectable medication is not limited to the typical "non-compliant" patient. Even compliant patients have exacerbations, and the paranoia and disorganization that accompanies these often lead to discontinuation of medication. This may increase the length and severity of the relapse. Injectable medications also allow more precise titration of dose and response, since the delivery of medication to the brain is more reliable than with oral medication and intermittent "missing" of a dose is less of an issue. Finally, intramuscular medication can result in less severe extrapyramidal side effects than oral preparations. Patients should be told that injectable medication will lower their risk of relapse and can reduce their total long-term neuroleptic exposure.

When arriving at a milligram dose for depot medication, it is reasonable to begin with a 1:1 oral-to-decanoate conversion for fluphenazine decanoate given every two or three weeks. Similarly, it is reasonable to begin with a 1:10 oral-to-decanoate conversion for haloperidol decanoate given monthly (22). For example, a patient who is taking $5 \mathrm{mg}$ haloperidol daily would be expected to require roughly $50 \mathrm{mg}$ of haloperidol decanoate per month. While there is variation between patients and disagreement about optimal conversion factors, these ratios provide good starting 
points. After beginning decanoate preparations, one must be sure to continue oral medications for at least one to two months, since it can take 3 to 5 doses of decanoate before a steady state is reached (23). While techniques have been developed for "loading" patients with decanoate without concomitant use of oral medication, gradual transition from oral to decanoate medication produces the most consistent plasma concentrations (24).

The long half-life of decanoate also dictates that upward or downward titration of decanoate dose, while important, should be done every 3 to 6 months. For the same reason, psychotic exacerbations while on decanoate should be treated by augmenting with oral medication, not necessarily increasing decanoate dose. Finally, it is important to be aware of the need for training in the injection of the viscous decanoate preparations. When typical intramuscular injection techniques are used the decanoate preparations can leak significantly at the injection site. Practitioners should, therefore, use a "Z-tracking" technique to ensure consistent medication delivery (25). Z-Tracking involves manually moving superficial tissue and muscle before decanoate injection so that the needle track does not remain contiguous with the injection site. Using a small gauge needle may also help reduce leakage.

\section{NOVEL MEDICATIONS}

Studies show that roughly one-third of people with schizophrenia show little improvement with traditional neuroleptic medications (11). These patients have been termed "neuroleptic nonresponders" (26). While strategies such as changing to a different neuroleptic, using a high dose, or augmenting with lithium occasionally help non-responsive patients, they generally prove ineffective (27). These nonresponsive patients have, however, been dramatically helped by the development of novel antipsychotic medications. This discussion will focus mainly on clozapine, since this is the only medication that has been clearly shown to be more effective than other antipsychotic medications. Another recently available antipsychotic medication is risperidone, an agent with significant antagonistic activity at dopamine, serotonin, and alpha-adrenergic receptors. It has been shown to have a unique side-effect profile, with a reduced liability for extrapyramidal symptoms at efficacious doses (28). The one large study examining this medication found that risperidone also improved negative symptoms, however, further research will be needed to determine whether this is secondary to a lower level of parkinsonian side-effects. In any case, as a result of risperidone's significant anti-serotonergic activity, it has a unique side-effect profile and has proven to be well tolerated. It has, on this basis, entered widespread use as an important clinical tool.

Clozapine, while more difficult to use than other antipsychotic medications, is clinically fairly well understood. Any community mental health organization that treats more than a few people with schizophrenia should be using clozapine. While much press has been made about clozapine's efficacy with the "negative" or deficit symptoms of schizophrenia, in fact all neuroleptic medications treat negative symptoms to some degree (29). Clozapine's usefulness appears to arise from the fact that 
it treats both negative and positive symptoms more effectively than any other available antipsychotic medication (30,31). While the efficacy of risperidone has not yet been adequately compared to clozapine, preliminary clinical experience suggests that it may not be as effective in severely ill patients. Clozapine is also useful because it is the only currently available antipsychotic medication that causes very few or no parkinsonian side effects. Finally, extensive experience with clozapine indicates that it causes very little or no tardive dyskinesia. In fact, tardive dyskinesia often improves with clozapine treatment (32), making this the medication of choice for people with psychotic illness and severe or progressive tardive movement disorders.

Given the risk of agranulocytosis, clozapine's use should usually be limited to the following clinical situations: 1) inadequate response to conventional antipsychotic medications, 2) disabling or progressive tardive dyskinesia, or 3) unmanageable side effects on other antipsychotic medications (33). Inadequate response to conventional agents is often interpreted as meaning that significant positive symptoms have persisted despite adequate trials of two different neuroleptic medications. There is no reason to suspect that clozapine should be limited to patients with any particular psychotic diagnoses. Clozapine has been shown to be effective in both schizophrenia and schizoaffective disorder, and has been successfully used in refractory bipolar disorder and borderline personality disorder with psychosis $(34,35)$. The only absolute contraindications to clozapine are a hematologic disorder predisposing to granulocytopenia, previous leukopenia with clozapine, and comatose states.

Clozapine can cause a number of side effects (36). Common minor side effects include sedation, excessive drooling and weight gain. Sedation often occurs with dosage increases, generally resolves with time, and can be minimized by giving the entire daily dose of clozapine at bedtime. Drooling can be managed by placing a towel on the pillow at night, or, if necessary, by using an anticholinergic medication. Weight gain is managed with dietary modification and exercise. Less frequent side effects include tachycardia, increased body temperature and orthostatic hypotension. Tachycardia and temperature increases are usually mild and often do not require intervention. They must, however, be differentiated from the more serious (and rare) Neuroleptic Malignant Syndrome. Orthostatic hypotension can often be managed by having the patient change position slowly, and increase fluid and salt intake. Overall, clozapine's minor side-effects are usually easy to manage. With the exception of weight gain, they generally resolve with time and are less severe if the medication dose is titrated up slowly. If attended to appropriately, they should rarely lead to medication discontinuation. In fact, most patients find clozapine's side-effects to be preferable to those associated with traditional neuroleptics.

Serious side effects of clozapine include respiratory arrest, seizure, and agranulocytosis. Respiratory arrest is quite rare, and seems more likely with the first dose and when the patient is taking a respiratory depressant. For this reason, patients should not be on benzodiazepines when starting clozapine. Also, all patients must start at a daily dose of $12.5 \mathrm{mg}$, and must restart at this dose after being off clozapine for more than one day. Seizures occur in $2-3 \%$ of patients at low doses (less than 450 $\mathrm{mg}$ ), in $5-6 \%$ of patients at higher doses (more than $650 \mathrm{mg}$ ), and appear to be 
related to the rate of dosage increase. Clozapine may not be used at doses above 900 mg per day. If a seizure occurs, the clozapine dose should be cut in half and the patient sent for neurologic evaluation. If this neurologic evaluation is normal, valproate can be begun and the clozapine dose slowly increased as needed. As with seizures caused by traditional neuroleptics, the seizures with clozapine are often readily controlled.

Agranulocytosis occurs in about $1 \%$ of patients (37), and death due to agranulocytosis has occurred in about $0.05 \%$ of patients. Deaths due to agranulocytosis may, however, be more than offset by reductions in mortality due to improved treatment of schizophrenia (38). Because all patients in the United States must have their white blood cell count tested weekly before receiving their medication, agranulocytosis is readily detected and treated. Between February 1990 and May 1992140 cases of agranulocytosis occurred, and there were 7 deaths related to agranulocytosis. All of these deaths occurred in patients who were at or above 40 years old (39). The first death was widely reported, and occurred in a patient who was also taking carbamazepine (40). Carbamazepine, and other medications that cause leukopenia, should be used with caution in patients on clozapine.

Over the year ending April 1992, twenty-three thousand patients were enrolled in clozapine treatment systems. These systems include a psychiatrist, a pharmacist and a laboratory, and require a great deal of paperwork and administrative effort. For this reason, pharmacists have created consulting groups which complete the paperwork and other administrative work associated with clozapine. Our clinicians have had success working with a local consulting business that charges the patient about $\$ 20$ per week for their services (41). They have made clozapine as easy to use as any other neuroleptic medication, and have facilitated our use of clozapine at a local public mental health clinic.

There have been a number of prominent obstacles to the use of clozapine in public mental health systems (42). Most of the people who would benefit from clozapine have severe chronic schizophrenia, and most of these people are treated in these public systems. Unfortunately, the availability of clozapine in the public sector has been guided more by administrative than clinical forces. These public systems have been accustomed to caring for the seriously ill while spending remarkably little money on psychiatric treatment. Patients are often seen every one to three months by psychiatrists who are allowed only a few minutes per patient to prescribe medication. Minimizing the role of psychiatrists has made the introduction of clozapine tragically slow in many public mental health clinics.

Public systems' reluctance to adopt new clinical technologies such as clozapine can be overcome by pressure from psychiatrists and consumer organizations. The National Alliance for the Mentally Ill was instrumental in the decision by the federal government to force state Medicaid programs to pay for clozapine. Unfortunately, many state and local governments have not implemented the clinical reforms necessary to actually make clozapine available in public clinics. The use of clozapine in these clinics requires education of clinic staff, an increase in clinical and adminis- 
trative resources for seriously ill patients, and supervision of a multi-disciplinary team by a psychiatrist who will prescribe clozapine.

\section{CONCLUSION}

Over the past decade, we have witnessed significant progress in the psychopharmacologic management of psychotic disorders. Minimal effective dosing, depot medication, and novel agents have significantly improved the response of schizophrenia to treatment. These new clinical technologies have not, however, been adopted by many of the public organizations that care for these patients. This lack of availability of state-of-the-art treatment has raised significant questions about the quality of care delivered in public systems (43). Improving this quality will begin with psychiatrists and consumer advocates who insist on the availability of these new clinical techniques.

\section{REFERENCES}

1. Marder SR, Wirshing WC, Van Putten T: Drug treatment of schizophrenia. Overview of recent research. Schizophr Res 1991; 4:81-90.

2. Kane JM, Marder SR: Psychopharmacologic treatment of schizophrenia. Schizophr Bull 1993; 19:287-302.

3. Baldessarini RJ, Cohen BM, Teicher MH: Significance of neuroleptic dose and plasma level in the pharmacological treatment of psychoses. Arch Gen Psychiatry 1988; 45:79-91.

4. Van Putten T, Marder SR, Mintz J: A controlled dose comparison of haloperidol in newly admitted schizophrenic patients. Arch Gen Psychiatry 1990; 47:754-758.

5. Donlon PT, Hopkin JT, Tupin JP, et al: Haloperidol for acute schizophrenic patients. An evaluation of three oral regimens. Arch Gen Psychiatry 1980; 37:691-695.

6. Van Putten T, Marder SR, Mintz J, Poland RE: Haloperidol plasma levels and clinical response: a therapeutic window relationship. Am J Psychiatry 1992; 149:500-5.

7. Palao DJ, Arauxo A, Brunet M, et al: Haloperidol: therapeutic window in schizophrenic. J Clin Psychopharmacol 1994; 14:303-310.

8. McEvoy JP, Hogarty GE, Steingard S: Optimal dose of neuroleptic in acute schizophrenia. A controlled study of the neuroleptic threshold and higher haloperidol dose. Arch Gen Psychiatry 1991; 48:739-45.

9. Janicak PG, Davis JM, Preskorn SH, Ayd FJ: Principles and Practice of Psychopharmacotherapy, lst ed. Baltimore MD, Williams \& Wilkins, 1993.

10. Baldessarini R: Chemotherapy in Psychiatry. Cambridge MA, Harvard University Press, 1985.

11. Brown WA, Herz LR: Neuroleptic response as a nosologic device, in Handbook of Schizophrenia, vol 3. New York NY, Elsevier, 1988.

12. Kuehnel TG, Liberman RP, Marshall BD, Bowen L: Optimal drug and behavior therapy for treatment-refractory institutionalized schizophrenics, in Effective Psychiatric Rehabilitation: New Directions for Mental Health Services, vol 53. Edited by Liberman R. San Francisco, Jossey-Bass, 1992.

13. Lingjaerde O: Benzodiazepines in the treatment of schizophrenia: an updated survey. Acta Psychiatr Scand 1991; 84:453-459. 
14. Kane JM, Woerner M, Weinhold P, et al: Incidence of tardive dyskinesia: five-year data from a prospective study. Psychopharmacol Bull 1984; 20:387-389.

15. Morgenstern H, Glazer WM: Identifying risk factors for tardive dyskinesia among longterm outpatients maintained with neuroleptic medications. Results of the Yale Tardive Dyskinesia Study. Arch Gen Psychiatry 1993; 50:723-33.

16. Hogarty GE, McEvoy JP, Munetz M, et al: Dose of fluphenazine, familial expressed emotion, and outcome in schizophrenia. Results of a two-year controlled study. Arch Gen Psychiatry 1988; 45:797-805.

17. Mintz J, Mintz LI, Phipps CC: Treatments of mental disorders and the functional capacity to work, in Handbook of Psychiatric Rehabilitation. Edited by Liberman RP. New York NY, Macmillan Publishing, 1992.

18. Wittlin BJ: Practical psychopharmacology, in Psychiatric Rehabilitation of Chronic Mental Patients. Edited by Liberman RP. Washington DC, American Psychiatric Press, 1988.

19. Wirshing WC, Eckman T, Liberman RP, Marder SR: Management of risk of relapse through skills training of chronic schizophrenics, in Advances in Neuropsychiatry and Psychopharmacology, Volume 1: Schizophrenia Research. Edited by Tamminga CA, Schultz SC. New York NY, Raven Press, 1991.

20. Overall JE, Gorham DR: The Brief Psychiatric Rating Scale (BPRS): recent developments in ascertainment and scaling. Psychopharmacol Bull 1988; 24:97-99.

21. Vaccaro JV, Young AS, Glynn S: Community-based care of individuals with schizophrenia. Combining psychosocial and pharmacologic therapies. Psychiatr Clin North Am 1993; 16:387-399.

22. Kane JM: Dosage strategies with long-acting injectable neuroleptics, including haloperidol decanoate. J Clin Psychopharmacol 1986; 6:20S-23S.

23. Marder SR, Hubbard JW, Van Putten T, Midha KK: Pharmacokinetics of long-acting injectable neuroleptic drugs: clinical implications. Psychopharmacol 1989; 98:433-439.

24. Ereshefsky L, Saklad SR, Tran-Johnson T, et al: Kinetics and clinical evaluation of haloperidol decanoate loading dose regimen. Psychopharmacol Bull 1990; 26:108-114.

25. Belanger M, Chouinard G: Techniques for injecting long-acting neuroleptics. Br J Psychiatry 1982; 141:316.

26. Christison GW, Kirch DG, Wyatt RJ: When symptoms persist: choosing among alternative somatic treatments for schizophrenia. Schizophr Bull 1991; 17:217-45.

27. Kinon BJ, Kane JM, Johns C, et al: Treatment of neuroleptic-resistant schizophrenic relapse. Psychopharmacol Bull 1993; 29:309-314.

28. Marder SR, Meibach RC: Risperidone in the treatment of schizophrenia. Am J Psychiatry 1994; 151:825-835.

29. Kane JM, Mayerhoff D: Do negative symptoms respond to pharmacological treatment? $\mathrm{Br}$ J Psychiatry 1989; 155 (supplement 7):115-118.

30. Kane J, Honigfeld G, Singer J, Meltzer H: Clozapine for the treatment-resistant schizophrenic. A double-blind comparison with chlorpromazine. Arch Gen Psychiatry 1988; 45:789-796.

31. Breier A, Buchanan RW, Kirkpatrick B, et al: Effects of clozapine on positive and negative symptoms in outpatients with schizophrenia. Am J Psychiatry 1994; 151:20-6.

32. Gerlach J, Peacock L: Motor and mental side effects of clozapine. J Clin Psychiatry 1994; 55:107-109.

33. Marder SR, Van Putten T: Who should receive chlozapine? Arch Gen Psychiatry 1988; 45:865-867. 
34. McElroy SL, Dessain EC, Pope HG, et al: Clozapine in the treatment of psychotic mood disorders, schizoaffective disorder, and schizophrenia. J Clin Psychiatry 1991; 52:41 1-414.

35. Frankenburg FR, Zanarini MC: Clozapine treatment of borderline patients: a preliminary study. Compr Psychiatry 1993; 34:402-405.

36. Lieberman JA, Kane JM, Johns CA: Clozapine: guidelines for clinical management. J Clin Psychiatry 1989; 50:329-338.

37. Alvir JM, Lieberman JA, Safferman AZ, et al: Clozapine-induced agranulocytosis. Incidence and risk factors in the United States. N Engl J Med 1993; 329:162-167.

38. Meltzer HY, Okayli G: Reduction of suicidality during clozapine treatment of neurolepticresistant schizophrenia: impact on risk-benefit assessment. Am J Psychiatry 1995; 152:183190.

39. Sandoz: Clozaril (clozapine) Treatment Trends. Jersey City NJ, Sandoz Pharmaceuticals, 1992.

40. Gerson SL, Lieberman JA, Friedenberg WR, et al: Polypharmacy in fatal clozapineassociated agranulocytosis. Lancet 1991; 338:262.

41. Young AS, Vaccaro JV: Making clozapine available. Hosp Community Psychiatry 1994; 45:831-832.

42. Reid WH: Access to care: clozapine in the public sector. Hosp Community Psychiatry 1990; 41:870-873.

43. Young AS, Clark GH: Guidelines for community psychiatric practice, in Community Psychiatrist: A Practitioners Manual. Edited by Vaccaro JV, Clark GH. Washington DC, American Psychiatric Press, in press. 